\title{
Adaptation to Aerobic Environment of Lactobacillus johnsonii/gasseri Strains
}

OPEN ACCESS

Edited by:

Claudio Fabricio Gonzalez, University of Florida, United States

Reviewed by:

Elisa Salvetti,

University College Cork, Ireland Jorge Reinheimer,

National University of the Littoral,

Argentina

Aleš Berlec,

Jožef Stefan Institute (IJS), Slovenia

${ }^{*}$ Correspondence: Gianluigi Mauriello giamauri@unina.it

Specialty section:

This article was submitted to Microbial Physiology and Metabolism, a section of the journal

Frontiers in Microbiology

Received: 14 December 2017

Accepted: 23 January 2018

Published: 09 February 2018

Citation:

Maresca D, Zotta $T$ and Mauriello G (2018) Adaptation to Aerobic Environment of Lactobacillus johnsonii/gasseri Strains.

Front. Microbiol. 9:157.

doi: 10.3389/fmich.2018.00157

\author{
Diamante Maresca', Teresa Zotta ${ }^{2}$ and Gianluigi Mauriello ${ }^{1 *}$ \\ ${ }^{1}$ Department of Agricultural Sciences, University of Naples Federico II, Portici, Italy, ${ }^{2}$ Institute of Food Science, National \\ Research Council, Avellino, Italy
}

Oxygen is considered one of the main factors affecting probiotic bacteria survival due to the induction of oxidative damages caused by the action of reactive oxygen species (ROS). It has been shown that oxidative stress resistance in lactic acid bacteria is strongly dependent on the type of cell metabolism. Shift from fermentative to respiratory metabolism (through the addition of heme and menaquinone and in presence of oxygen) was associated to increase in biomass, long-term survival, and production of antioxidant enzymes. The aim of this work was to investigate the effect of aerobic (presence of oxygen) and respiratory (presence of oxygen, heme, and menaquinone) cultivation on the growth kinetic, catalase production, oxygen uptake, and oxidative stress response of Lactobacillus johnsonii/gasseri strains previously isolated from infant feces. Seven strains showed to consume oxygen under aerobic and respiratory conditions. The strain AL5 showed a catalase activity in both growth conditions, while AL3 showed this activity only in respiratory condition. Respiratory condition improved their tolerance to oxidative compounds (hydrogen peroxide and ROS generators) and further they showed promising probiotic features. The exploration of respiratory competent phenotypes with probiotic features may be extremely useful for the development of competitive starter or probiotic cultures.

Keywords: oxidative stress response, probiotic bacteria, antimicrobial activity, lactic acid bacteria, respiration metabolism

\section{INTRODUCTION}

The greatest challenge of the probiotic bacteria is enduring stresses encountered during food processing and gastrointestinal transit (Mills et al., 2011). Probiotic performances and robustness can be compromised by exposure to various environmental stresses, including acid, cold, drying, starvation, oxidative, and osmotic stresses, that may affect the physiological status and the functional properties of bacterial cells (Zhang and $\mathrm{Li}, 2013$ ). Survival to harsh conditions is an essential prerequisite for probiotic bacteria before reaching the target site where they can exert their health promoting effects (Expert Committee FAO/WHO, 2002). Several probiotics, in fact, have shown a poor resistance to technological processes, limiting their use to a restricted number of food products. The presence of oxygen is considered one of the main factors affecting the survival of probiotic lactic acid bacteria (LAB), anaerobic aerotolerant microorganisms, which lack the capability to synthesize an active electron transport chain. The aerobic environment in 
LAB may induce the production of toxic oxygen by-products (reactive oxygen species, ROS, such as superoxide anion radical, hydroxyl radical, and hydrogen peroxide) that may damage DNA, proteins, and lipids, resulting in cellular death (Amaretti et al., 2013). Moreover, hydrogen peroxide can further react with some cations $\left(\mathrm{Fe}^{2+}\right.$ and $\left.\mathrm{Cu}^{2+}\right)$ leading to highly reactive oxidants via Fenton reaction (De Angelis and Gobetti, 2004; Kang et al., 2013). LAB get their energy mainly through substrate level phosphorylation, and lack both heme containing enzymes and active cytochrome oxidases, which are essential components for oxygen-linked energy metabolism (Kang et al., 2013). However, most LAB can grow under aerobic conditions and their simplest way to utilize oxygen is through the action of flavoprotein oxidases (NADH oxidase, NOX; pyruvate oxidase, POX; lactate oxidase, LOX; $\alpha$-glycerophosphate oxidase, and L-amino acid oxidase) that use substrates such as pyruvate or NADH (Yamamoto et al., 2011). The activity of these enzymes, however, may result in the accumulation of toxic $\mathrm{H}_{2} \mathrm{O}_{2}$. LAB can prevent the oxidative damage by producing several ROS-degrading enzymes [catalase, superoxide dismutase (SOD), flavin-dependent oxidase, and peroxidases] and different redox and repair systems (glutathione and thioredoxin systems) and antioxidant enzymes [catalase, pseudo-catalase, SOD, and NADH peroxidases (NPR)] (Rochat et al., 2006; Kullisaar et al., 2010; Ruiz et al., 2011; Amaretti et al., 2013). Several authors have demonstrated that oxidative stress resistance in some LAB species is dependent on the type of metabolism and that the shift from fermentative toward respiratory metabolisms may increase their growth, long-term survival and stress tolerance (Gaudu et al., 2002; Rezaiki et al., 2004; Pedersen et al., 2012; Guidone et al., 2013; Ianniello et al., 2015). These effects are likely associated to the activation of the electron transport chain by growing cells in presence of oxygen, heme, and menaquinone (vitamin K2). Heme is an essential cofactor in heme-dependent catalase and cytochrome $b d$ oxidase (CydAB) synthesis (Pedersen et al., 2008). Catalase can degrade $\mathrm{H}_{2} \mathrm{O}_{2}$ and protect the cell from oxidative damage, while $\mathrm{CydAB}$ can catalyze the rapid reduction of oxygen to water as well as to increase the ATP production. Instead, menaquinone may act as a central respiratory chain component delivering electrons from reducers (such as NADH dehydrogenase) to terminal oxidases (such as CydAB) (Brooijmans et al., 2009). However, while respiration metabolism and oxidative stress response have been extensively studied in Lactococcus lactis (Zotta et al., 2014; Ianniello et al., 2015) and Lactobacillus casei (Miyoshi et al., 2003; Zotta et al., 2014; Ianniello et al., 2015) and Lactobacillus plantarum groups (Watanabe et al., 2012; Zotta et al., 2012, 2013; Guidone et al., 2013) limited data are available for the strains of Lactobacillus johnsonii and Lactobacillus gasseri. These species are genetically related and belong to Lactobacillus delbrueckii group (Sun et al., 2014). L. johnsonii and L. gasseri are reported as the dominant bacteria within the lactobacilli population in human gut and in vaginal microbiota and are described as strict anaerobes with fermentative energy metabolism (Pridmore et al., 2003). Current data on oxygen tolerance and oxidative stress response in L. johnsonii are limited to the probiotic strain NCC 533 (Hertzberger et al., 2013, 2014). These authors have observed that the endogenous production of $\mathrm{H}_{2} \mathrm{O}_{2}$ is the main cause of oxidative stress in L. johnsonii NCC 533 during its aerobic growth, even though the presence of oxygen relieves its carbon dioxide $\left(\mathrm{CO}_{2}\right)$ and acetate dependence, compared to anaerobic growth. On the contrary, no data on the capability to activate a minimal respiratory chain are available for $L$. johnsonii and L. gasseri species. The aim of this work was to evaluate the effect of aerobic (presence of oxygen) and respiratory (presence of oxygen, heme, and menaquinone) cultivation on the growth ability of $L$. gasseri and L. johnsonii strains. Tolerance of oxidative stress and other functional features [i.e., survival to simulated oral-gastrointestinal transit (OGIT) and antimicrobial activity] were also evaluated in order to select new promising probiotic strains.

\section{MATERIALS AND METHODS}

\section{Strains and Culture Conditions}

A pool of 145 isolates potentially belonging to Lactobacillus genus were previously isolated from infant feces at the University of Naples and used in this study. L. johnsonii DSM $10533^{\mathrm{T}}$, L. johnsonii DSM 20533, L. gasseri DSM $20243^{\mathrm{T}}$, L. gasseri DSM 20077, and Lactobacillus rhamnosus ATCC 53103 (commercially known as GG strain) were used as reference strains. All lactobacilli were routinely propagated in Weissella Medium Broth (WMB; Zotta et al., 2012) pH 6.8 or in MRS Agar and incubated in anaerobiosis at $37^{\circ} \mathrm{C}$ for $24 \mathrm{~h}$. Nine strains belonging to potential pathogenic and spoilage species (Table 2) were used in antimicrobial activity tests.

\section{Molecular Characterization of Isolates}

Genomic DNA was extracted using the Insta-Gene matrix (BioRad, Milan, Italy) according to the manufacturer's protocol, with some modifications. Briefly, two to three colonies of each microorganism were suspended in $0.05 \mathrm{M}$ phosphatebuffered saline (PBS) $\mathrm{pH} 7.0$ and centrifuged for $1 \mathrm{~min}$ at $10,000 \mathrm{~g}$. Pellet was dissolved in $200 \mu \mathrm{l}$ of InstaGene matrix and incubated at $56^{\circ} \mathrm{C}$ for $30 \mathrm{~min}$ (Thermomixer Comfort, Eppendorf). After vortexing for $10 \mathrm{~s}$, sample was treated for $8 \mathrm{~min}$ at $100^{\circ} \mathrm{C}$. Mixture was centrifuged at $10,000 \mathrm{~g}$ for $3 \mathrm{~min}$ and the resulting supernatant, containing the bacterial DNA, was used for PCR. Quality and quantity of DNA was assessed using a NanoDrop spectrophotometer 1000 (Thermo Scientific, Milan, Italy).

In order to avoid the presence of clones, the isolates were firstly analyzed by rep-PCR using oligonucleotide GTG $_{5}\left(5^{\prime}\right.$-GTG GTG GTG GTG GTG-3') primer (Invitrogen, Life Technologies, Milan, Italy). The reaction was performed in $20 \mu \mathrm{l}$ mixtures containing: $50 \mathrm{ng}$ DNA template, $2.5 \mu \mathrm{l}$ of $10 \times$ PCR Buffer (Invitrogen, Milan, Italy), $50 \mathrm{mM} \mathrm{MgCl}, 10 \mathrm{mM}$ dNTPs mix, $10 \mu \mathrm{M}$ primer, and Taq Polymerase (Bio-Rad) $5 \mathrm{U} / \mu \mathrm{l}$. PCR was carried out using an initial denaturation step at $95^{\circ} \mathrm{C}$ for $4 \mathrm{~min}$, followed by 35 cycles of $1 \mathrm{~min}$ at $94^{\circ} \mathrm{C}, 1 \mathrm{~min}$ at $40^{\circ} \mathrm{C}$, and $1 \mathrm{~min}$ at $72^{\circ} \mathrm{C}$ each, and by a final extension of $8 \mathrm{~min}$ at $72^{\circ} \mathrm{C}$. PCR products were separated by electrophoresis $(3 \mathrm{~h}$ at $130 \mathrm{~V})$ on $1.7 \%$ $(\mathrm{w} / \mathrm{v})$ agarose gel stained with $0.1 \mu \mathrm{l} / \mathrm{ml}$ SYBR safe (Invitrogen) 
and visualized by UV transillumination. Rep-PCR profiles were analyzed by BioNumerics 5.0 software (Applied Maths) using Pearson's correlation coefficient with UPGMA (Unweighted Pair Group Method with Arithmetic Mean) clustering of averaged profile similarities.

Universal primers (Invitrogen) fD1 (5'-AGAGTTTGATC CTGGCTCAG-3') and rD1 (5'-AAGGAGGTGATCCAGCC- $\left.3^{\prime}\right)$ were used to amplify the $16 \mathrm{~S}$ rRNA gene of isolates. PCR reaction mixture (final volume $50 \mu \mathrm{l}$ ) contained $50 \mathrm{ng}$ of DNA template, $5 \mu \mathrm{l}$ of $10 \times$ buffer (200 mM Tris- $\mathrm{HCl} \mathrm{pH} 8.4,500 \mathrm{mM} \mathrm{KCl}$ ), $25 \mathrm{mM} \mathrm{MgCl}_{2}, 10 \mathrm{mM}$ dNTPs mix, primers $50 \mathrm{pM}$, and Taq Polymerase $5 \mathrm{U} / \mu \mathrm{l}$. PCR amplification was performed using an initial denaturation step at $95^{\circ} \mathrm{C}$ for $3 \mathrm{~min}$, followed by 30 cycles of $45 \mathrm{~s}$ at $94^{\circ} \mathrm{C}, 45 \mathrm{~s}$ at $55^{\circ} \mathrm{C}$ and $1 \mathrm{~min}$ at $72^{\circ} \mathrm{C}$ each, and by a final extension of $5 \mathrm{~min}$ at $72^{\circ} \mathrm{C}$. The PCR products were separated by on agarose gel $1.5 \%(\mathrm{w} / \mathrm{v})$, containing $0.1 \mu \mathrm{l} / \mathrm{l}$ SYBR safe, purified using QIAquick PCR Purification Kit (Qiagen, Milan, Italy), and sequenced by Primm srl (Milan, Italy). Research for DNA similarity was performed using the BLAST program of the National Center for Biotechnology Information ( $\mathrm{NCBI}^{1}$ ) GenBank. Strains showing a \% similarity higher than $98 \%$ with L. johnsonii/gasseri were used for further analyses.

\section{Preliminary Evaluation of Probiotic Potential of Isolates}

The ability of $L$. johnsonii/gasseri strains to survive in simulated OGIT was performed according to Vizoso et al. (2006) with some modifications. Briefly, overnight cultures were recovered by centrifugation $(6500 \mathrm{~g}$ for $10 \mathrm{~min}$ ), washed twice with sterile saline $(\mathrm{NaCl} 0.85 \%)$ and suspended in equal volume of simulated saliva juice (SSJ: $\mathrm{NaCl} 5 \mathrm{~g} / \mathrm{l}, \mathrm{KCl} 2.2 \mathrm{~g} / \mathrm{l}, \mathrm{CaCl}_{2} 0.22 \mathrm{~g} / \mathrm{l}, \mathrm{NaHCO}_{3}$ $1.2 \mathrm{~g} / \mathrm{l}$, and lysozyme $100 \mathrm{mg} / \mathrm{l}, \mathrm{pH}$ 6.9) and incubated for $5 \mathrm{~min}$ at $37^{\circ} \mathrm{C}$. The suspension was then centrifuged as above, re-suspended in an equal volume of simulated gastric juice (SGJ: $\mathrm{NaCl} 5 \mathrm{~g} / \mathrm{l}, \mathrm{KCl} 2.2 \mathrm{~g} / \mathrm{l}, \mathrm{CaCl}_{2} 0.22 \mathrm{~g} / \mathrm{l}, \mathrm{NaHCO}_{3} 1.2 \mathrm{~g} / \mathrm{l}$, and pepsin $3 \mathrm{~g} / \mathrm{l}, \mathrm{pH} 2.5$ ) and incubated at $37^{\circ} \mathrm{C}$ for $120 \mathrm{~min}$ under gentle agitation $(200 \mathrm{rpm})$ to simulate peristalsis. After centrifugation, pellet was re-suspended in an equal volume of simulated pancreatic juice (SPJ: $\mathrm{NaHCO}_{3} 6.4 \mathrm{~g} / \mathrm{l}, \mathrm{KCl} 0.239 \mathrm{~g} / \mathrm{l}$, $\mathrm{NaCl} 1.28 \mathrm{~g} / \mathrm{l}, 0.5 \%$ bile salts, and $0.1 \%$ pancreatin, $\mathrm{pH}$ 7.0) and incubated at the same condition of SGJ. Survival (\%) was calculated after each treatment. L. rhamnosus GG was used as positive control in this experiment.

Antimicrobial activity was assayed using an agar spot test and a well diffusion agar test, as previously described by Banerjee et al. (2013). In the first case, $10 \mu \mathrm{l}$ of each overnight culture were spotted onto a MRS Agar plate. After incubation at $37^{\circ} \mathrm{C}$ for $24 \mathrm{~h}$, plate was overlaid with $10 \mathrm{ml}$ of Tryptone Soya Broth (TSB, Oxoid, Milan, Italy) supplemented with $0.75 \%$ agar (TSB soft agar) previously inoculated with the indicator strains (Table 2) to reach a final concentration of $1 \times 10^{6} \mathrm{CFU} / \mathrm{ml}$. After $24 \mathrm{~h}$ of incubation at optimal growth temperature of indicator strains the antimicrobial activity was detected by the presence of a clear growth inhibition zone around the colony of tested strain. In the well diffusion agar test, a cell free supernatant was recovered

\footnotetext{
${ }^{1}$ http://blast.ncbi.nlm.nih.gov/Blast.cgi
}

by centrifugation ( $6500 \mathrm{~g}$ for $10 \mathrm{~min}$ ), adjusted at $\mathrm{pH} 6.5$ with $\mathrm{NaOH} 1 \mathrm{M}$, heat-treated for $10 \mathrm{~min}$ at $80^{\circ} \mathrm{C}$ and sterilized by a low-binding protein $0.22 \mu \mathrm{m}$ pore size filter. Fifty microliters of supernatant were placed into a $6 \mathrm{~mm}$-diameter well, done in a TSB soft agar plate previously inoculated with the indicator strain at a final concentration of $1 \times 10^{6} \mathrm{CFU} / \mathrm{ml}$. After incubation at optimal growth temperature of indicator strain, the antimicrobial activity was determined by measuring the diameter $(\mathrm{cm})$ of the inhibition zone around the wells. In both agar spot test and a well diffusion agar test results were calculated as the mean of three experiments. The strains that showed antimicrobial activity in well diffusion agar test were further tested to investigate the nature of the antimicrobial substance produced. The sensitivity to different enzymes was tested using $10 \mathrm{mg} / \mathrm{ml}$ (final solution) of lipase, catalase, papain, trypsin, $\alpha$-chymotrypsin, pronase $\mathrm{E}$, and pepsin in PBS. Ten microliters of solution used in well diffusion assay were spotted onto TSB soft agar plates previously inoculated with the indicator strain. Afterward, $8 \mu$ l of enzyme solution were deposited adjacent the spot of supernatant to inhibit the activity of antimicrobial substance.

\section{Aerobic and Respiratory Growth and Catalase Production}

The assessment of aerobic and respiratory growth as well as the presence of catalase activity were performed as reported by Zotta et al. (2014). Strains were cultivated for $24 \mathrm{~h}$ at $37^{\circ} \mathrm{C}$ in 24 -well microplates in different growth conditions: anaerobic (AN, static cultivation in modified WMB with $10 \mathrm{~g} / \mathrm{l}$ of glucose, $\mathrm{pH} 6.8$, with AnaeroGen bags, Oxoid), aerobic (AE, in modified WMB, shaken on a rotary shaker at $150 \mathrm{rpm}$ ), and respiratory (RS, AE growth in modified WMB, supplemented with $2.5 \mu \mathrm{g} / \mathrm{ml}$ of hemin and $1 \mu \mathrm{g} / \mathrm{ml}$ of menaquinone) cultivations. Micro-plates were inoculated $(2 \% \mathrm{v} / \mathrm{v})$ with standardized [optical density at $\left.650 \mathrm{~nm}\left(\mathrm{OD}_{650}\right)=1.0\right]$ overnight anaerobic pre-cultures and incubated for $24 \mathrm{~h}$ at $37^{\circ} \mathrm{C}$. At the end of incubation, the OD and $\mathrm{pH}$ values were measured. Catalase activity was qualitatively evaluated by re-suspending the washed biomass derived from $1 \mathrm{ml}$ of culture in all different conditions (AN, AE, and RS) in $100 \mu \mathrm{l}$ of a $3 \%(\mathrm{v} / \mathrm{v}) \mathrm{H}_{2} \mathrm{O}_{2}$ solution. Catalase production was revealed by an evident formation of bubbles in the cell suspension. Three independent replicates were carried out for each experiment.

Strains that showed $\mathrm{H}_{2} \mathrm{O}_{2}$-degrading capability were further tested to quantify the enzymatic activity. Five milliliters of AN, $\mathrm{AE}$, and RS cultures standardized at $\mathrm{OD}_{650}=1$ were centrifuged at $13,000 \mathrm{~g}$ for $5 \mathrm{~min}$ and the resulting pellet mixed with $1.0 \mathrm{ml}$ of $60 \mathrm{mM} \mathrm{H}_{2} \mathrm{O}_{2}$ in $50 \mathrm{mM}$ PBS pH 7. The activity was measured at $240 \mathrm{~nm}$ after $3 \mathrm{~min}$ incubation at room temperature. Results were expressed as units $(\mathrm{U})$ per $\mathrm{ml}$ of solution and calculated according to the following formula:

$$
\mathrm{U}=(\Delta \mathrm{OD} \times \varepsilon \times d f) /(t \times v)
$$

where,

$\triangle \mathrm{OD}$ : decrease in absorbance after $3 \mathrm{~min}$ at $240 \mathrm{~nm}$; $\varepsilon: 39.4 \mathrm{M}^{-1} / \mathrm{cm}^{-1}$, extinction coefficient of $\mathrm{H}_{2} \mathrm{O}_{2}$ at $240 \mathrm{~nm}$; $d f$ : dilution factor; $t$ : time of analysis in min; $v$ : volume of sample. 


\section{Oxygen Uptake}

The consumption of oxygen in AN, AE, and RS growing cells was measured as described by Ricciardi et al. (2014). Briefly, washed and standardized $\left(\mathrm{OD}_{650}=1\right)$ biomass was re-suspended in air-saturated solution of $5.5 \mathrm{mM}$ glucose and $0.002 \mathrm{~g} / \mathrm{l}$ of resazurin sodium salt (Sigma) in $0.1 \mathrm{M} \mathrm{PBS} \mathrm{pH}$ 7. The discoloration time (DT, expressed in minutes) from blue oxidized form (resazurin) to colorless reduced form (dihydroresorufin) was used as indicator of oxygen uptake. The strain Pseudomonas fragi SP1 was used as positive control.

\section{Effect of Aerobic and Respiratory Cultivation on Oxidative Stress Tolerance}

$\mathrm{AN}, \mathrm{AE}$, and RS cultures, washed twice and standardized $\left(\mathrm{OD}_{650}=1\right)$ in $0.1 \mathrm{M}$ PBS $\mathrm{pH} 7.0$, were loaded in 96well microplates and exposed to different concentrations (from 0.62 to $320 \mathrm{mM}$ serial twofold dilution in $0.1 \mathrm{M}$ PBS $\mathrm{pH}$ 7.0) of $\mathrm{H}_{2} \mathrm{O}_{2}$, menadione and pyrogallol for $30 \mathrm{~min}$ at $37^{\circ} \mathrm{C}$ in anaerobiosis. Stressed cultures were inoculated $(10 \% \mathrm{v} / \mathrm{v})$ in sterile WMB broth $(20 \mathrm{~g} / \mathrm{l}$ glucose, $\mathrm{pH} 6.8$; 96-well microplates) and the surviving cells were detected by evaluating the medium turbidity (presence/absence) after $24 \mathrm{~h}$ of incubation at $37^{\circ} \mathrm{C}$ in anaerobic conditions. For each strain the results were expressed as maximum tolerated concentration $(\mathrm{mM})$ of oxidative stress compounds (Table 4).

\section{In Silico Analysis of Genes Involved in Aerobic-Respiratory Pathway and Oxidative Stress Response}

The presence of genes coding for the main enzymes involved in oxygen utilization (pyruvate oxidase, pox; acetate kinase, ack; lactate oxidase, lox; NADH oxidase, nox), electron transport chain (NADH dehydrogenase, ndh; cytochrome bd oxidase, cydABCD operon; menaquinone biosynthesis complex, menFDXBEC, and ubiquinone/menaquinone biosynthesis methyltransferase, $u b i E$ ) and oxidative stress response (hemeand manganese-dependent catalases, kat and Mnkat; manganesedependent SOD, sodA; thioredoxin/thioredoxin reductase system, trx-trxB; glutathione peroxidase/reductase system, gop and gor; NADH peroxidase, $n p r$ ) was evaluated in the finished, draft and permanent draft genomes of L. johnsonii and L. gasseri from IMG/M database ${ }^{2}$ (Supplementary Table S1). The occurrence expressed in \% (Occ) of each gene in the L. johnsonii and L. gasseri group was calculated. The sequences retrieved from the genomes of L. lactis subsp. cremoris MG1363 (menFDXBEC), L. plantarum WCFS1 (pox, ack, lox, nox, npr, cydABCD, ubiE, kat, trxA-trxB, gopgor), L. plantarum ATCC 14431 (Mn-kat), and Lactobacillus sakei $23 \mathrm{~K}(\operatorname{sod} A)$ were used as queries. Sequence similarity was detected using the default cut-off parameter $(\%$ of identity) obtained by ClustalW2 multiple sequence alignment tool.

${ }^{2}$ https://img.jgi.doe.gov

\section{RESULTS}

\section{Molecular Characterization of Strains Belonging to L. johnsonii/gasseri Species}

On the basis of genotypic (rep-PCR analysis) and phenotypic (i.e., cell and colony morphology, growth performance, planktonic or aggregated growth in MRS broth) characteristics, a total of 80 strains were selected and subjected to $16 \mathrm{~S}$ rRNA gene sequencing analysis. Results of BLAST analysis showed that 55 strains belonging to L. johnsonii/gasseri species ( $\geq 98 \%$ homology), while the remaining 25 strains to L. casei (15 strains) and L. plantarum groups (10 strains). Since $16 \mathrm{~S}$ rRNA gene sequence is not discriminative for L. johnsonii and L. gasseri species, in all experiments we decided to indicate the strains as L. johnsonii/gasseri. On the basis of the different rep-PCR profiles, 34 strains of L. johnsonii/gasseri were selected and used to investigate the potential probiotic features and the capability to grow in presence of oxygen and oxidative stress conditions.

\section{Survival to Simulated OGIT}

Results of viable counts of the strains after simulated OGIT showed that all strains were significantly $(P<0.05)$ resistant (at least the $50 \%$ of initial population) to SSJ exposure (Table 1). On the contrary, the number of survivors to SGJ and SPJ dramatically decreased. Only 13 and 6 strains had at least $50 \%$ of viable cells $(P<0.05)$ after the exposure to SGJ and SPJ, respectively (Table 1). Specifically, the six strains tolerant of SPJ showed more than $90 \%$ of survival. As expected, the probiotic strain L. rhamnosus GG showed a high resistance to OGIT (>90\% of final survival).

\section{Antimicrobial Activity}

Results of agar spot test showed that 22 strains of L. johnsonii/gasseri exhibited antimicrobial activity against at least two of the nine indicator strains used in this study (data not shown). In Table 2 are reported the strains with the widest inhibitory pattern. The strains AL5, AL3, and ALA had the highest antimicrobial activity against the most of indicators (diameter of inhibition halos $>2 \mathrm{~cm}$ ). On the other hand, results of well-diffusion agar assay showed that only the strains BM4, AL5, BR32, AL3, ID5AN, BM1CM, and BM61CG produced antimicrobial substances, although they inhibited only Staphylococcus aureus DSM 20231 (data not shown). Inhibition was not associated to the production of bacteriocinlike substances or $\mathrm{H}_{2} \mathrm{O}_{2}$ since the antagonistic activities were not affect by the action of proteolytic enzymes and catalase.

TABLE 1 | Strains showing a survival $\geq 50 \%$ after exposure to the different conditions of oral-gastrointestinal transit.

\begin{tabular}{lcc}
\hline SSJ & SGJ & SPJ \\
\hline All strains & AL5, BR32, ID5AN, ID7AN, AL8, ALJ, & AL5, BR32, ID5AN, \\
& AL3, BM1CM, BM1CP, BR35, AL15, & ID7AN, AL3, \\
& L. johnsonii 10533 ${ }^{\top}$, L. gasseri 20243 ${ }^{\top}$ & L. johnsonii 10533
\end{tabular}




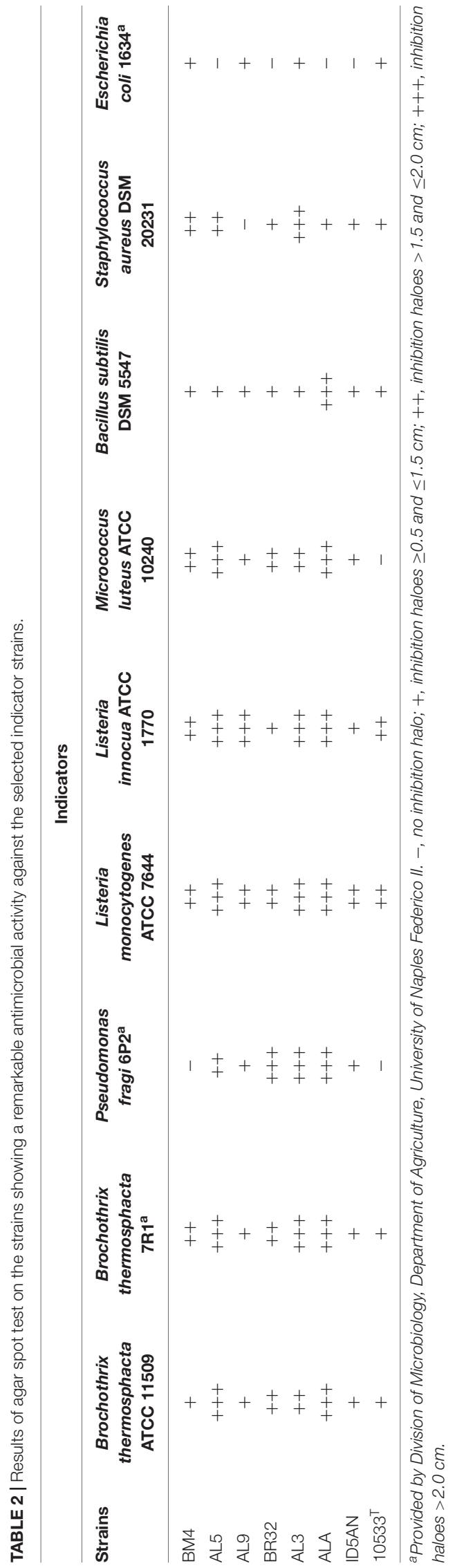

\section{Aerobic and Respiratory Promoting Growth, Oxygen Uptake, and Catalase Production}

Ratios between $\mathrm{OD}$ and $\mathrm{pH}$ values (AE/AN, RS/AN) measured in the different growth conditions were calculated and used to identify the phenotype of each strain. Specifically, when both OD and $\mathrm{pH}$ ratios in $\mathrm{AE} / \mathrm{AN}$ were $>1$ (Figure 1, upper right side), strains were indicated as oxygen tolerant phenotypes (OTP); when $\mathrm{OD}$ and $\mathrm{pH}$ ratios in RS/AN were $>1$ (Figure 2, upper right side), strains were indicated as respiration-competent phenotypes (RCP). Results showed that 14 strains had both OTP and RCP, while two strains had only the RCP. For these 16 strains, the OD and $\mathrm{pH}$ ratios in $\mathrm{RS} / \mathrm{AE}$ were also calculated (Figure 3 ) and the oxygen uptake was tested. Results showed that 12 strains grew better when hemin and menaquinone were supplied (Figure 3, upper right side), while four strains grew better when only oxygen was supplied (Figure 3, upper left side). Interestingly, the four strains showing OD ratio RS/AE $<1$ (AL5, AL15, BM32, and $\mathrm{BM} 6 \mathrm{CG})$ and the three strains showing the best growth performance in RS (ALJ, AL3, and BM4) resulted to be the strains that consumed oxygen during their growth (DT $<180 \mathrm{~min}$, Table 3). Consistently, ALJ, AL3, and BM4 consumed more oxygen in RS than in AE, AL5 consumed more oxygen in AE and BM6CG, unexpectedly, consumed oxygen only in AE cultivation. Instead, AL15 and BM32 showed the same DT in both AE and RS (Table 3). Catalase activity was detected only in two strains. Specifically, AL5 showed 11.30, 12.20, and $12.00 \mathrm{U}$ of enzymatic activity in AN, AE, and RS, respectively, while AL3 showed catalase activity only in RS with $13.50 \mathrm{U}$.

\section{Effect of Aerobic and Respiratory Conditions on the Oxidative Stress Tolerance}

In order to investigate the effect of growth conditions on oxidative stress tolerance the strains cultivated in $\mathrm{AN}, \mathrm{AE}$, and RS conditions were exposed to generators of superoxide anion (menadione and pyrogallol) and $\mathrm{H}_{2} \mathrm{O}_{2}$. Strains cultivated in AE exhibited the lowest tolerance of all oxidative compounds (Table 4). For several strains, the respiratory growth increased the resistance to $\mathrm{H}_{2} \mathrm{O}_{2}$. Most of respiratory growing cultures had $\mathrm{H}_{2} \mathrm{O}_{2}$-tolerance similar to that of cells grown under anaerobic conditions, while only AL9 had a lower resistance when cultivated in presence of oxygen, hemin, and menaquinone. Compared to anaerobic conditions, respiration promoted the menadione resistance only in five strains and impaired the survival in AL9, BM6CG, and BM1CM. With exception of AL9, the resistance of respiratory cultures to pyrogallol was similar to that of anaerobically growing cells.

\section{In Silico Analysis of Genes Involved in Aerobic-Respiratory Metabolism and Oxidative Stress Response (Supplementary Table S1)}

Results of in silico analysis showing the occurrence \% of identity (\% ID) of each gene are indicated in Supplementary Table S1. 


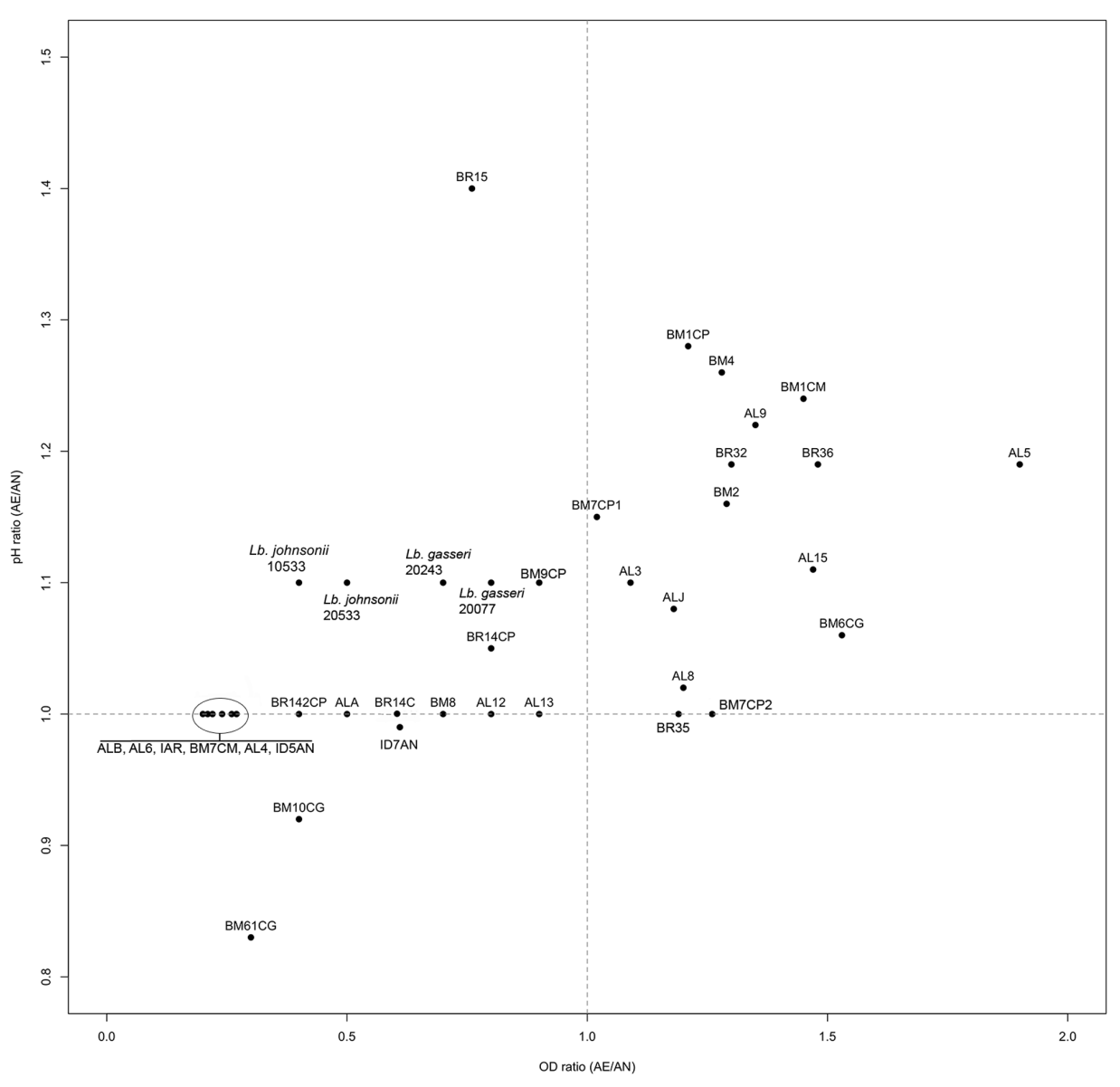

FIGURE 1 | Scatter plot of $\mathrm{OD}_{650}$ ratio against $\mathrm{pH}$ ratio in $\mathrm{AE} / \mathrm{AN}$ of $L$. johnsonii/gasseri strains.

Interestingly, we found $100 \%$ of occurrence of genes pox, ack, $\operatorname{cyd} A, \operatorname{cydB}, u b E, \operatorname{trx} A$, and $\operatorname{tr} x B$ both in L. johnsonii and in L. gasseri. Instead, remaining genes were found at very low $\%$ in both species, with exclusion of gor gene that was found in all L. johnsonii genomes and lacking in only two L. gasseri genomes. Moreover, an ID in the range $45-55 \%$ was registered for most of genes. Finally, the genes kat, Man-kat, sodA, menFDXBEC, and nox, not reported in the table, have been never annotated in genomes of L. johnsonii and L. gasseri.

\section{DISCUSSION}

This study investigated the adaptive response of promising probiotic L. johnsonii/gasseri strains to switch from fermentative to aerobic and respiratory metabolism and the effect of this metabolic pathway on oxidative stress response. We found that about $70 \%$ of lactobacilli isolated from baby stools belonged to L. johnsonii/gasseri species. This result is in agreement with findings of many authors (Wall et al., 2006; Mitsou et al., 2008; Morelli et al., 2008), who demonstrated that L. johnsonii/gasseri species are the more commonly homofermentative lactobacilli isolated in newborns and infant feces. According to the
FAO/WHO definition, probiotics are "live microorganisms which, when administered in adequate amounts, confer a health benefit on the host" (Expert Committee FAO/WHO, 2002). In order to perform their physiological role, probiotics bacteria must overcome a number of stresses before they reach the target site (Kwarteng et al., 2015). The ability to survive the gastrointestinal transit and the antimicrobial activity are two important features of probiotics (Vizoso et al., 2006). In this study, $34 \mathrm{~L}$. johnsonii/gasseri strains were screened for the ability to pass through OGIT. All strains showed a strong resistance to saliva juice, suggesting a high ability to survive in the presence of lysozyme. On the contrary, for most strains the viability decreased when exposed to simulated gastric and intestinal juice. Six strains, however, showed a great resistance to OGIT, with levels of survival comparable to those of L. rhamnosus GG, suggesting their possible use as probiotic supplements.

The capability to inhibit the growth of pathogenic and spoilage bacteria varied among L. johnsonii/gasseri strains. The inhibitory activity demonstrated with agar spot test could be due to a lowering of $\mathrm{pH}$ due to organic acids production; indeed, it disappeared when free cell supernatants were neutralized. However, the ability to produce organic acids should be a useful feature to reduce colonization of pathogenic microorganisms 


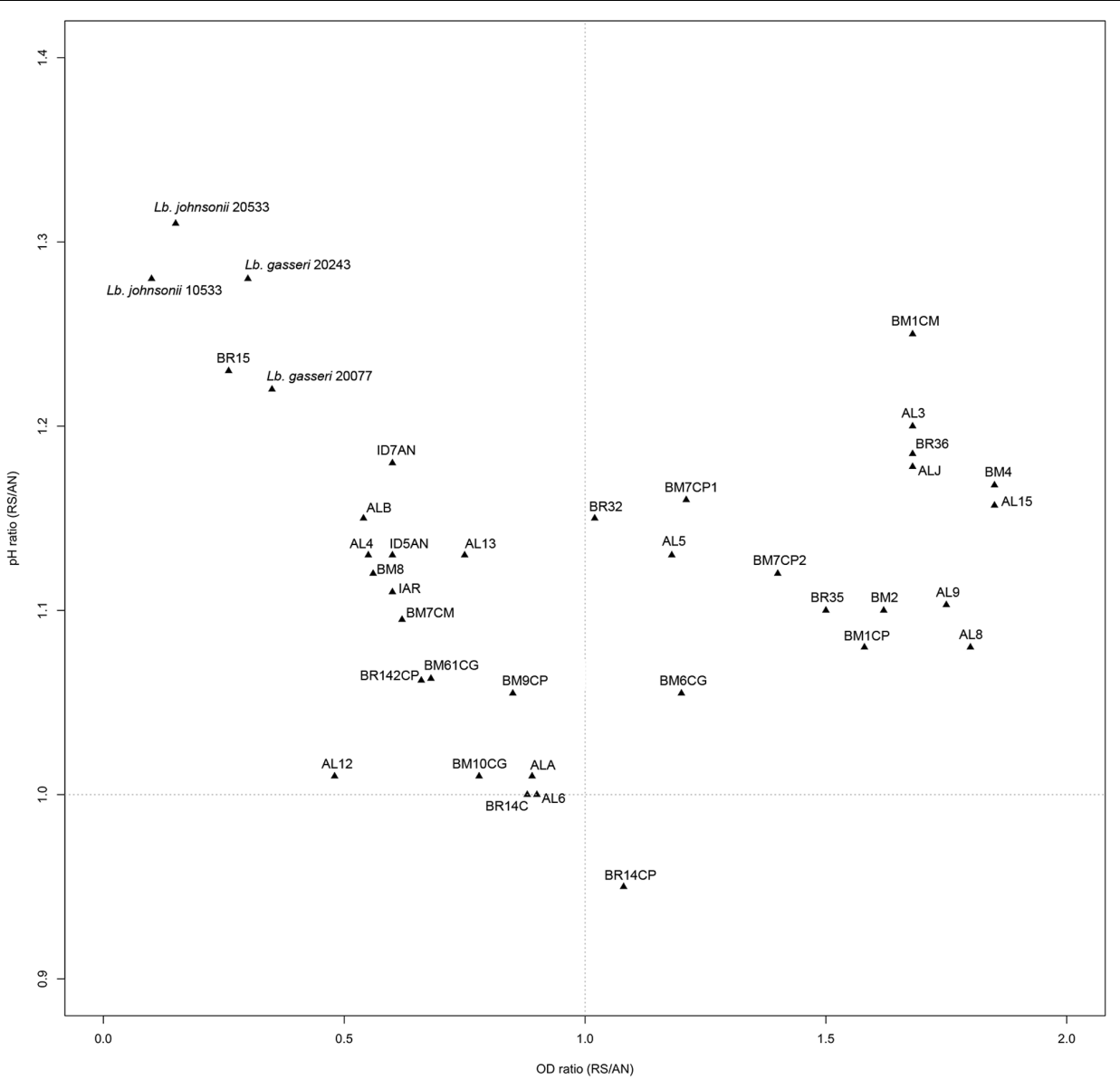

FIGURE 2 | Scatter plot of $\mathrm{OD}_{650}$ ratio against $\mathrm{pH}$ ratio in $\mathrm{RS} / \mathrm{AN}$ of $L$. johnsonii/gasseri strains.

in human GIT. Tejero-Sariñena et al. (2012) showed that the production of organic acids by different probiotic strains reduced the growth of potential pathogenic microorganisms. In presence of low $\mathrm{O}_{2}$ concentration, acetic acid and $\mathrm{H}_{2} \mathrm{O}_{2}$ may be produced by some probiotic strains. Pridmore et al. (2008) described the ability of some L. johnsonii and L. gasseri strains to produce $\mathrm{H}_{2} \mathrm{O}_{2}$ and acetic acid, with antimicrobial activity against Salmonella Typhimurium SLI344. In this study, the neutralized cell-free supernatants had inhibitory activity against $S$. aureus. Since bacteriocin-like and $\mathrm{H}_{2} \mathrm{O}_{2}$ activities were excluded, we hypothesized that the inhibition may be due to the production of neutral compounds or some undissociated short chain free fatty acids with antimicrobial activity (Huang et al., 2011; Ricke, 2014; Aldunate et al., 2015). However, further investigations are needed to reveal the nature of antimicrobial substances produced by L. johnsonii and L. gasseri active against S. aureus.

A large diversity on the capability to grow in presence of oxygen and/or respiratory cofactors was present within the L. johnsonii and L. gasseri strains and on the basis of growth performances and oxygen consumption it was possible to group the strains in: (i) oxygen-tolerant anaerobes, capable to grow in aerobic and respiratory conditions, but not able to consume oxygen (i.e., AL8, AL9, BM2, BM1CM, BM1CP,
BM7CP1, BM7CP2, BR35, and BR36); (ii) aerobic phenotypes, able to consume oxygen and for which aerobiosis was the best growth condition compared to respiration (i.e., AL5, AL15, $\mathrm{BM} 32$, and BM6CG); (iii) respiratory phenotypes, able to consume oxygen and for which respiration was the best growth condition compared to aerobiosis (i.e., ALJ, AL3, and BM4); (iv) oxygen-sensitive anaerobes, unable to grow in both aerobic and respiratory conditions (remaining strains). Hertzberger et al. (2013) evaluated for the first time the response of $L$. johnsonii NCC 533 to oxidative conditions. Compared to anaerobiosis, the presence of oxygen relieved the acetate and $\mathrm{CO}_{2}$ growth dependencies of the strain, but induced more rapidly the entry in stationary phase. In this study, we found four strains (AL5, BM6CG, AL15, and BR32) with aerobic phenotype that showed increased biomass production, reduced acidification, and oxygen uptake capability, suggesting a possible activation of aerobic metabolism. In several LAB strains, the stimulatory effect of oxygen was shown to be dependent by POX and acetate kinase (ACK) activities (Goffin et al., 2006; Quatravaux et al., 2006). According to results of in silico analysis, L. johnsonii and L. gasseri possess genes predicted to encode for both POX and ACK $(\mathrm{Occ}=100 \%)$, the main enzymes involved in aerobic pathway (Pridmore et al., 2008). In presence of oxygen and at low 


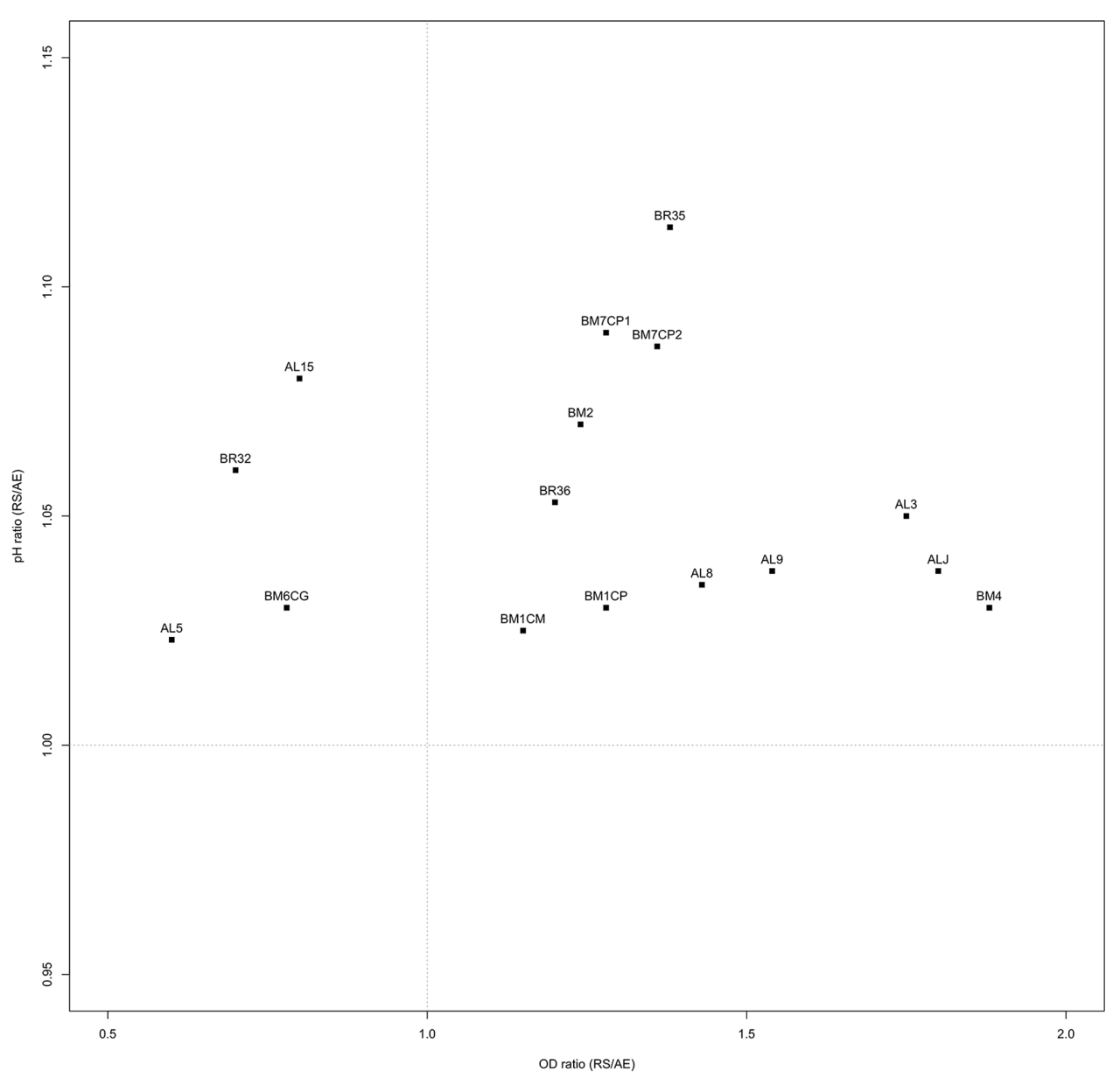

FIGURE 3 | Scatter plot of $\mathrm{OD}_{650}$ ratio against $\mathrm{pH}$ ratio in $\mathrm{RS} / \mathrm{AE}$ of $L$. johnsonii/gasseri strains.

glucose concentration, pyruvate can be metabolized by POXACK pathway, allowing the production of acetate, $\mathrm{CO}_{2}$ and extra ATP biosynthesis (Pedersen et al., 2012). Therefore, in our strains the possible POX-ACK pathway activation could directly explain the observed physiological consequence, such as increase of $\mathrm{pH}$ due to a possible conversion of pyruvate into acetate and increase of OD due to extra ATP generation. As a matter of fact, Hertzberger et al. (2013) demonstrated that pox deletion in L. johnsonii NCC 533 resulted in a slower growth rate and a growth arrest upon $\mathrm{CO}_{2}$ depletion, confirming the positive role of POX-ACK pathway. The respiratory growth was never investigated in L. johnsonii/gasseri strains. Like the aerobic metabolism adaptation, the ability to shift toward respiratory pathway was strain-specific. In this study, we found that the strains AL3, ALJ, and BM4 had a respiratory phenotype. Like most LAB, the genomes of L. johnsonii and L. gasseri lack the genes for menaquinone and heme biosynthesis, but harbor those for the cytochrome oxidase production (Occ $=100 \%)$. Thus, in these species, the respiratory metabolism may occur only when heme and menaquinone are supplied (Pedersen et al., 2012). As well as in all lactobacilli, the mechanism of heme uptake is unknown. However, heme-binding proteins and heme homeostasis systems have been investigated in several LAB strains competent for aerobic respiration (Gaudu et al., 2003; Lechardeur et al., 2010, 2011; Sawai et al., 2012). In several LAB strains, the growth in presence of oxygen may result in the production and accumulation of $\mathrm{H}_{2} \mathrm{O}_{2}$ and ROS. Pridmore et al. (2008) and Hertzberger et al. (2013) demonstrated that the accumulation of $\mathrm{H}_{2} \mathrm{O}_{2}$ due to LOX and POX activity was the primary reason of oxidative stress in L. johnsonii NCC 533. Therefore, the ability to scavenge $\mathrm{H}_{2} \mathrm{O}_{2}$ and ROS may contribute to the survival in aerobic conditions. Surprisingly, we found that two strains showed a catalase like activity. Specifically, the strain AL5 in all growth conditions, while the strain AL3 only in RS conditions. Heme and manganese-catalase activity has been previously studied in several LAB species (Knauf et al., 1992; Rochat et al., 2006; Guidone et al., 2013; Ianniello et al., 2015, 2016) but this is the first study reporting catalase positive phenotype in L. johnsonii/gasseri strains. However, genes encoding for heme-catalase or Mn-catalase were never annotated in L. johnsonii and L. gasseri genomes. Heme-dependent and Mn-dependent catalase activities were previously found in the respiration-competent strain L. casei N87 (Zotta et al., 2014; Ianniello et al., 2015,2016) and the genome sequence confirmed 
TABLE 3 | Consumption of oxygen in Lactobacillus johnsonii/gasseri strains expressed as discoloration time in minutes (DT) of the redox indicator resazurin.

\begin{tabular}{|c|c|c|c|}
\hline \multirow[t]{2}{*}{ Strains } & \multicolumn{3}{|c|}{ Growth conditions } \\
\hline & AN & $\mathrm{AE}$ & RS \\
\hline AL9 & $>180$ & $>180$ & $>180$ \\
\hline AL5 & $>180$ & 90 & 120 \\
\hline AL15 & $>180$ & 100 & 100 \\
\hline AL8 & $>180$ & $>180$ & $>180$ \\
\hline BR32 & $>180$ & 100 & 100 \\
\hline BM4 & $>180$ & 130 & 75 \\
\hline BM7CP2 & $>180$ & $>180$ & $>180$ \\
\hline BR35 & $>180$ & $>180$ & $>180$ \\
\hline BM6CG & $>180$ & 120 & $>180$ \\
\hline BM1CP & $>180$ & $>180$ & $>180$ \\
\hline BR36 & $>180$ & $>180$ & $>180$ \\
\hline BM2 & $>180$ & $>180$ & $>180$ \\
\hline BM7CP1 & $>180$ & $>180$ & $>180$ \\
\hline $\mathrm{BM} 1 \mathrm{CM}$ & $>180$ & $>180$ & $>180$ \\
\hline ALJ & $>180$ & 120 & 100 \\
\hline AL3 & $>180$ & 110 & 75 \\
\hline Pseudomonas fragi SP1 & ND & 65 & ND \\
\hline
\end{tabular}

$A N$, anaerobiosis; $A E$, aerobiosis; $R S, A E$ growth supplemented with $2.5 \mu \mathrm{g} / \mathrm{ml}$ of hemin and $1 \mu \mathrm{g} / \mathrm{ml}$ of menaquinone.

the presence of both genes (Zotta et al., 2016). We sequenced whole genome of the strains AL3 and AL5 (Maresca et al., 2017) and a first sequence analysis showed that both strains do not possess genes for heme- and manganese-catalase. However, these strains as well as the stains AL15, BR36, BM2, and ALJ showed a higher resistance to $\mathrm{H}_{2} \mathrm{O}_{2}$ and ROS generators when cultivated in RS, compared to $\mathrm{AN}$ and $\mathrm{AE}$ conditions. Results of genome analysis (Maresca et al., 2017) revealed that AL3 and AL5 genomes have sequences encoding for NOX and NPR, the main enzymes involved in the $\mathrm{NAD}(\mathrm{P})$-dependent $\mathrm{H}_{2} \mathrm{O}_{2}$ scavenging pathway in LAB. On the other hand, the increased resistance to $\mathrm{H}_{2} \mathrm{O}_{2}$ under $\mathrm{RS}$ condition due to NPR activity was previously demonstrated in L. rhamnosus GG, L. casei Shirota and in some respiration-competent strains of $L$. casei (Ianniello et al., 2015). Moreover, all strains were able to cope to menadione and pyrogallol stress in both RS and AN condition. The genome analysis of AL3 and AL5 strains revealed the presence of large pattern of genes involved in oxidative stress resistance mechanisms (Maresca et al., 2017). Surprisingly, the results of genome analysis revealed that AL3 and AL5 genomes have sequences encoding for the antioxidant enzyme SOD, Dpslike peroxide resistance protein (DPR) and for the complete thioredoxin reductase system. Noteworthy, SOD sequences are relatively rare in Lactobacillus genus and occur only in some strains of Lactobacillus sanfranciscensis, L. sakei, Lactobacillus curvatus, and Lactobacillus paracasei species (Yamamoto et al., 2011; Zotta et al., 2017). This is the first time that sod gene was annotated in L. gasseri genome. Dpr is a member of the DNA-binding proteins from starved cells (Dps) that are able to provide cell protection during exposure to harsh environmental stress, including oxidative stress and nutritional deprivation. The function of Dpr has been the object of numerous studies and its role in acid and oxidative stress (iron and hydrogen peroxide detoxification) resistance in Escherichia coli, has been proposed (Calhoun and Kwon, 2011). While, regarding to LAB, the role of Dpr in the oxidative stress response was reported only in some species of Streptococcus and in L. lactis (Pulliainen et al., 2003; Cesselin et al., 2011). Finally, thioredoxin reductase system belong to flavoprotein disulfide oxidoreductases family and play a significant role in oxidative stress resistance, maintaining a high

TABLE 4 | Tolerance of $\mathrm{H}_{2} \mathrm{O}_{2}$, menadione and pyrogallol (expressed as maximum tolerated concentration; mM) in L. johnsonii/gasseri strains grown under AN, AE, and RS conditions.

\begin{tabular}{|c|c|c|c|c|c|c|c|c|c|}
\hline \multirow[t]{2}{*}{ Strains } & \multicolumn{3}{|c|}{$\mathrm{H}_{2} \mathrm{O}_{2}(\mathrm{mM})$} & \multicolumn{3}{|c|}{ Menadione (mM) } & \multicolumn{3}{|c|}{ Pyrogallol (mM) } \\
\hline & AN & $\mathrm{AE}$ & RS & AN & $\mathrm{AE}$ & RS & AN & $\mathrm{AE}$ & RS \\
\hline AL9 & 20 & 0 & 1.25 & 10 & 0 & 0 & 160 & 10 & 10 \\
\hline AL5 & 10 & 10 & 40 & 2.5 & 5 & 20 & 320 & 80 & 320 \\
\hline AL15 & 20 & 10 & 40 & 0.62 & 1.25 & 5 & 320 & 80 & 320 \\
\hline AL8 & 20 & 5 & 20 & 5 & 0 & 5 & 80 & 2.5 & 80 \\
\hline BR32 & 20 & 2.5 & 20 & 1.25 & 1.25 & 5 & 80 & 40 & 80 \\
\hline BM4 & 20 & 20 & 20 & 5 & 2.5 & 5 & 320 & 80 & 320 \\
\hline BM7CP2 & 20 & 5 & 20 & 2.5 & 0.62 & 2.5 & 80 & 20 & 80 \\
\hline BR35 & 20 & 5 & 20 & 5 & 0 & 2.5 & 80 & 20 & 80 \\
\hline BM6CG & 20 & 0 & 20 & 10 & 0 & 5 & 80 & 0 & 80 \\
\hline $\mathrm{BM} 1 \mathrm{CP}$ & 20 & 5 & 20 & 5 & 1.25 & 5 & 80 & 2.5 & 80 \\
\hline BR36 & 10 & 5 & 40 & 10 & 5 & 20 & 80 & 20 & 80 \\
\hline BM2 & 20 & 10 & 40 & 2.5 & 2.5 & 2.5 & 320 & 40 & 80 \\
\hline BM7CP1 & 20 & 10 & 20 & 2.5 & 2.5 & 2.5 & 80 & 40 & 80 \\
\hline $\mathrm{BM} 1 \mathrm{CM}$ & 20 & 2.5 & 20 & 10 & 0 & 5 & 80 & 0 & 80 \\
\hline ALJ & 5 & 2.5 & 20 & 2.5 & 0 & 2.5 & 40 & 40 & 80 \\
\hline AL3 & 10 & 10 & 40 & 2.5 & 0 & 20 & 80 & 40 & 80 \\
\hline
\end{tabular}

Growth conditions: AN, anaerobiosis; AE, aerobiosis; $R S$, AE growth supplemented with $2.5 \mu \mathrm{g} / \mathrm{ml}$ of hemin and $1 \mu \mathrm{g} / \mathrm{ml}$ of $\mathrm{menaquinone.}$ 
intracellular thiol/disulfide homeostasis in both prokaryotic and eukaryotic cells (Harel and Storz, 2000; Jänsch et al., 2007). Its role in oxygen and $\mathrm{H}_{2} \mathrm{O}_{2}$ tolerance have been explored in some Lactobacillus species (Li et al., 2003; Vido et al., 2005; Serrano et al., 2007; Jänsch et al., 2011; Serata et al., 2012). In conclusion, we investigated $34 \mathrm{~L}$. johnsonii/gasseri strains from baby stools and found that some of them showed both typical probiotic features, like resistance to OGIT and antimicrobial activity, and aerobic environment adaptation. In particular, the strains AL5, BR32, and AL3 showed to tolerate very well the stress due to OGIT, in fact more than $90 \%$ of their population survived this treatment. Furthermore, they showed to inhibit the growth of most of indicator strains used in this study by producing organic acids, and the growth of a $S$. aureus strain by producing a sort of antimicrobial substance, not ascribable to a protein or to hydrogen peroxide, that will be further investigated. Additionally, they showed an interesting adaptation to aerobic environment with the AL5 and BR32 strains showing an OTP and the AL3 strain showing a RCP. Their overall enhanced resistance to

\section{REFERENCES}

Aldunate, M., Srbinovski, D., Hearps, A., Latham, C., Ramsland, O., Gugasyan, R., et al. (2015). Antimicrobial and immune modulatory effects of lactic acid and short chain fatty acids produced by vaginal microbiota associated with eubiosis and bacterial vaginosis. Front. Physiol. 6:164. doi: 10.3389/fphys.2015.00164

Amaretti, A., di Nunzio, M., Pompei, A., Raimondi, S., Rossi, M., and Bordoni, A. (2013). Antioxidant properties of potentially probiotic bacteria: in vitro and in vivo activities. Appl. Microbiol. Biotechnol. 97, 809-817. doi: 10.1007/s00253012-4241-7

Banerjee, S. P., Dora, K., and Chowdhury, S. (2013). Detection, partial purification and characterization of bacteriocin produced by Lactobacillus brevis FPTLB3 isolated from freshwater fish. J. Food Sci. Technol. 50, 17-25. doi: 10.1007/ s13197-011-0240-4

Brooijmans, R., Smit, B., Santos, F., Riel, J. V., de Vos, W. M., and Hugenholtz, J. (2009). Heme and menaquinone induced electron transport in lactic acid bacteria. Microb. Cell Fact. 8, 28-31. doi: 10.1186/1475-2859-8-28

Calhoun, L., and Kwon, L. (2011). Structure, function and regulation of the DNAbinding protein Dps and its role in acid and oxidative stress resistance in Escherichia coli: a review. J. Appl. Microbiol. 110, 375-386. doi: 10.1111/j.13652672.2010.04890.x

Cesselin, B., Derré-Bobillot, A., Fernandez, A., Lamberet, G., Lechardeur, D., and Yamamoto, Y. (2011). "Responses of lactic acid bacteria to oxidative stress," in Stress Responses in Lactic Acid Bacteria, eds E. Tsakalidou and K. Papadimitriou (Berlin: Springer).

De Angelis, M., and Gobetti, M. (2004). Environmental stress responses in Lactobacillus: a review. Proteome 4, 106-122. doi: 10.1002/pmic.20030049

Expert Committee FAO/WHO (2002). Guidelines for the Evaluation of Probiotics in Foods. London: Food and Agricultural Organization of the United Nations.

Gaudu, P., Lamberet, G., Poncet, S., and Gruss, A. (2003). CcpA regulation of aerobic and respiration growth in Lactococcus lactis. Mol. Microbiol. 50, 183-192. doi: 10.1046/j.1365-2958.2003.03700.x

Gaudu, P., Vido, K., Cesselin, B., Kulakauskas, S., Tremblay, J., Rezaiki, L., et al. (2002). Respiration capacity and consequences in Lactococcus lactis. Antonie Van Leeuwenhoek 82, 263-269. doi: 10.1023/A:1020635600343

Goffin, P., Muscariello, L., Lorquet, F., Stukkens, A., Prozzi, D., Sacco, M., et al. (2006). Involvement of pyruvate oxidase activity and acetate production in the survival of Lactobacillus plantarum during the stationary phase of aerobic growth. Appl. Environ. Microbiol. 72, 7933-7940. doi: 10.1128/AEM.00659-06

Guidone, A., Ianniello, R. G., Ricciardi, A., Zotta, T., and Parente, E. (2013). Aerobic metabolism and oxidative stress tolerance in the Lactobacillus plantarum group. Word J. Microbiol. Biotechnol. 29, 1713-1722. doi: 10.1007/ s11274-013-1334-0 oxidative stressors and the evidence of catalase production ability of AL5 and AL3 strains confirmed this adaptation. Probiotic strains of this type could effectively work both during biomass production and in food or processing in which the aerobic condition could be a limiting factor for a standard probiotic strain.

\section{AUTHOR CONTRIBUTIONS}

All authors listed have made a substantial, direct and intellectual contribution to the work, and approved it for publication.

\section{SUPPLEMENTARY MATERIAL}

The Supplementary Material for this article can be found online at: https://www.frontiersin.org/articles/10.3389/fmicb. 2018.00157/full\#supplementary-material

Harel, O. C., and Storz, S. (2000). Roles of the glutathione and thioredoxindependent reduction systems in the Escherichia coli and Saccharomyces cerevisiae responses to oxidative stress. Annu. Rev. Microbiol. 54, 439-461. doi: 10.1146/annurev.micro.54.1.439

Hertzberger, R. Y., Arents, J., Dekker, H., Pridmore, R. D., Gysler, C., Kleerebezem, M., et al. (2014). $\mathrm{H}_{2} \mathrm{O}_{2}$ production in species of the Lactobacillus acidophilus group: a central role for a novel NADH-dependent flavin reductase. Appl. Environ. Microbiol. 80, 2229-2239. doi: 10.1128/AEM.04272-13

Hertzberger, R. Y., Pridmore, R. D., Gysler, C., Kleerebezem, M., and de Mattos, M. (2013). Oxygen relieves the $\mathrm{CO}_{2}$ and acetate dependency of Lactobacillus johnsonii NCC 533. PLOS ONE 8:e57235. doi: 10.1371/journal.pone.0057235

Huang, C. B., Alimova, Y., Myers, T., and Ebersole, G. L. (2011). Shortand medium-chain fatty acids exhibit antimicrobial activity for oral microorganisms. Arch. Oral Biol. 50, 650-656. doi: 10.1016/j.archoralbio.2011. 01.011

Ianniello, R. G., Zheng, J., Zotta, T., Ricciardi, A., and Ganzle, M. G. (2015). Biochemical analysis of respiratory metabolism in the heterofermentative Lactobacillus spicheri and Lactobacillus reuteri. J. Appl. Microbiol. 119, 763-775. doi: $10.1111 /$ jam. 12853

Ianniello, R. G., Zotta, T., Matera, A., Genovese, F., Parente, E., and Ricciardi, A. (2016). Investigation of factors affecting aerobic and respiratory growth in the oxygen-tolerant strain Lactobacillus casei N87. PLOS ONE 11:e0164065. doi: 10.1371/journal.pone.0164065

Jänsch, A., Freiding, S., Behr, J., and Vogel, R. F. (2011). Contribution of the NADH-oxidase (Nox) to the aerobic life of Lactobacillus sanfranciscensis DSM20451 ${ }^{\mathrm{T}}$. Food Microbiol. 28, 29-37. doi: 10.1016/j.fm.2010.08.001

Jänsch, A., Korakli, M., Vogel, R. F., and Ganzle, M. G. (2007). Glutathione reductase from Lactobacillus sanfranciscensis DSM20451 ${ }^{\mathrm{T}}$ : contribution to oxygen tolerance and thiol exchange reactions in wheat sourdoughs. Appl. Environ. Microbiol. 76, 4469-4476. doi: 10.1128/AEM.02322-06

Kang, T. S., Korber, D. R., and Tanaka, T. (2013). Influence of oxygen on NADH recycling and oxidative stress resistance systems in Lactobacillus panis PM1. AMB Express 3, 10-13. doi: 10.1186/2191-0855-3-10

Knauf, H. J., Vogel, R. F., and Hammes, W. P. (1992). Cloning, sequence and phenotypic expression of katA, which encodes the catalase of Lactobacillus sake LTH677. Appl. Environ. Microbiol. 58, 832-839.

Kullisaar, T., Songiseppb, E., Aunapuuc, M., Kilka, K., Arendc, A., Mikelsaarc, M., et al. (2010). Complete glutathione system in probiotic Lactobacillus fermentum ME31. Appl. Biochem. Mcrobiol. 46, 481-486. doi: 10.1134/S0003683810050030

Kwarteng, J. O., Debrah, K., Akabanda, F., and Jespersen, L. (2015). Technological properties and probiotic potential of Lactobacillus fermentum strains isolated from West African fermented millet dough. BMC Microbiol. 15:261. doi: 10. 1186/s12866-015-0602-6 
Lechardeur, D., Cesselin, B., Fernandez, A., Lamberet, G., Garrigues, G., and Pedersen, M. (2011). Using heme as an energy boost for lactic acid bacteria. Curr. Opin. Biol. 22, 143-149. doi: 10.1016/j.copbio.2010.12.001

Lechardeur, D., Fernandez, A., Robert, B., Gaudu, P., Trieu-Cuot, P., Lamberet, G., et al. (2010). The 2-Cys peroxiredoxin alkyl hydroperoxide reductase $\mathrm{c}$ binds heme and participates in its intracellular availability in Streptococcus agalactiae. J. Biol. Chem. 285, 16032-16041. doi: 10.1074/jbc.M109.024505

Li, Y., Hugenholtz, J., Abee, T., and Molenaar, D. (2003). Glutathione protects Lactococcus lactis against oxidative stress. Appl. Environ. Microbiol. 69, 5739-5745. doi: 10.1128/AEM.69.10.5739-5745.2003

Maresca, D., De Filippis, F., Tytgat, H. L. P., de Vos, W. M., and Mauriello, G. (2017). Draft genome sequences of the aerobic strains Lactobacillus gasseri AL3 and AL5. Genome Announc. 5:e0213-17. doi: 10.1128/genomeA.00213-17

Mills, S., Stanton, C., Fitzgerald, G. F., and Ross, R. P. (2011). Enhancing the stress responses of probiotics for a lifestyle from gut to product and back again. Microb. Cell Fact. 10:S19. doi: 10.1186/1475-2859-10-S1-S19

Mitsou, E. K., Kirtzalidou, E., Oikonomou, I., Liosis, G., and Kyriacou, A. (2008). Fecal microflora of Greek healthy neonates. Anaerobe 14, 94-101. doi: 10.1016/ j.anaerobe.2007.11.002

Miyoshi, A., Rochat, T., Gratadoux, G., Oliveira, Y., Langella, P., and Azevedo, V. (2003). Oxidative stress in Lactococcus lactis. Genet. Mol. Res. 2, 348-359.

Morelli, L., Cesena, C., de Haen, C., and Gozzini, L. (2008). Taxonomic Lactobacillus composition of feces from human newborns during the first few days. Microb. Ecol. 35, 205-212. doi: 10.1007/s002489900076

Pedersen, M. B., Garrigues, C., Tuphile, K., Brun, C., Vido, K., Bennedsen, M., et al. (2008). Impact of aeration and heme-activated respiration on Lactococcus lactis gene expression: identification of a heme-responsive operon. J. Bacteriol. 190, 4903-4911. doi: 10.1128/JB.00447-08

Pedersen, M. B., Gaudu, P., Lechardeur, D., Petit, M. A., and Gruss, A. (2012). Aerobic respiration metabolism in lactic acid bacteria and uses in biotechnology. Annu. Rev. Food Sci. Technol. 3, 37-58. doi: 10.1146/annurevfood-022811-101255

Pridmore, D., Pittet, A., Praplan, F., and Cavadini, C. (2008). Hydrogen peroxide production by Lactobacillus johnsonii NCC533 and its role in anti-Salmonella activity. FEMS Microbiol. Lett. 283, 210-215. doi: 10.1111/j.1574-6968.2008. 01176.x

Pridmore, R., Berger, B., Desiere, F., Vilanova, F., Barretto, C., Pittet, A., et al. (2003). The genome sequence of the probiotic intestinal bacterium Lactobacillus johnsonii NCC 533. Proc. Natl. Acad. Sci. U.S.A. 101, 2512-2517. doi: 10.1073/ pnas.0307327101

Pulliainen, A. T., Haataja, S., Kähkönen, S., and Finne, J. (2003). Molecular basis of $\mathrm{H}_{2} \mathrm{O}_{2}$ resistance mediated by Streptococcal Dpr. demonstration of the functional involvement of the putative ferroxidase center by site-directed mutagenesis in Streptococcus suis. J. Biol. Chem. 7, 7996-8005. doi: 10.1074/jbc. M210174200

Quatravaux, S., Remize, F., Bryckaert, E., Colavizza, D., and Guzzo, J. (2006). Examination of Lactobacillus plantarum lactate metabolism side effects in relation to the modulation of aeration parameters. J. Appl. Microbiol. 101, 903-912. doi: 10.1111/j.1365-2672.2006.02955.x

Rezaiki, L., Cesseli, B., Yamamoto, Y., Vido, K., West, E., and Gaudu, P. (2004). Respiration metabolism reduces oxidative and acid stress to improve long-term survival of Lactococcus lactis. Mol. Microbiol. 53, 1331-1342. doi: 10.1111/j. 1365-2958.2004.04217.x

Ricciardi, A., Ianniello, R. G., Tramutola, A., Parente, E., and Zotta, T. (2014). Rapid detection assay for oxygen consumption in the Lactobacillus casei group. Ann. Microbiol. 4, 1861-1864. doi: 10.1111/j.1365-2672.2006. 02955.x

Ricke, S. C. (2014). Perspectives on the use of organic acids and short chain fatty acids as antimicrobials. Poult. Sci. 82, 632-639. doi: 10.1093/ps/82.4.632

Rochat, T., Gratadoux, J., Gruss, A., Corthier, G., and Maguin, E. (2006). Production of a heterologous non heme catalase by Lactobacillus casei: an efficient tool for removal of $\mathrm{H}_{2} \mathrm{O}_{2}$ and protection of Lactobacillus bulgaricus from oxidative stress in milk. Appl. Environ. Microbiol. 72, 5143-5149. doi: 10.1128/AEM.00482-06

Ruiz, L., Gueimonde, M., Ruas-Madiedo, P., Ribbera, A., de los Reyes-Gavilán, C., Ventura, M., et al. (2011). Molecular clues to understand the aerotolerance phenotype of Bifidobacterium animalis subsp. lactis. Appl. Environ. Microbiol. 78, 644-650. doi: 10.1128/AEM.05455- 11
Sawai, H., Yamanaka, M., Sugimoto, H., Shiro, Y., and Aono, H. (2012). Structural basis for the transcriptional regulation of heme homeostasis in Lactococcus lactis. J. Biol. Chem. 28, 30755-30768. doi: 10.1074/jbc.M112.370916

Serata, M., Lino, T., Yasuda, E., and Sako, T. (2012). Roles of thioredoxin and thioredoxin reductase in the resistance to oxidative stress in Lactobacillus casei. Microbiology 158(Pt 4), 953-962. doi: 10.1099/mic.0.053942-0053942

Serrano, L. M., Molenaar, D., Wels, M., Teusink, B., Bron, P., de Vos, W., et al. (2007). Thioredoxin reductase is a key factor in the oxidative stress response of Lactobacillus plantarum WCFS1. Microb. Cell Fact. 6, 29-31. doi: 10.1186/14752859-6-29

Sun, Z., Harris, M. B., McCann, A., Guo, C., Argimo, S., and Zhang, W. (2014). Expanding the biotechnology potential of lactobacilli through comparative genomics of 213 strains and associated genera. Nat. Commun. 6:8322. doi: $10.1038 /$ ncomms 9322

Tejero-Sariñena, S., Barlow, J., Costabile, A., Gibson, G. S., and Rowland, J. (2012). In vitro evaluation of the antimicrobial activity of a range of probiotics against pathogens: evidence for the effects of organic acids. Anaerobe 18, 530-538. doi: 10.1016/j.anaerobe.2012.08.004

Vido, K., Diemer, H., Dorsselaer, A., Leize, E., Juillard, V., Gruss, A., et al. (2005). Roles of thioredoxin reductase during the aerobic life of Lactococcus lactis. J. Bacteriol. 187, 601-610. doi: 10.1128/JB.187.2.601-610.2005

Vizoso, M., Charles, M. A. P., Schillinger, F., and Holzapfel, W. P. (2006). Lactobacillus spp. with in vitro probiotic properties from human faeces and traditional fermented products. Int. J. Food Microbiol. 109, 205-214. doi: 10.1016/j.ijfoodmicro.2006.01.029

Wall, R., Fitzgerald, G., Hussey, S., Ryan, T., Murphy, B., Ross, P., et al. (2006). Genomic diversity of cultivable Lactobacillus populations residing in the neonatal and adult gastrointestinal tract. FEMS Microbiol. Ecol. 59, 127-137. doi: 10.1111/j.1574-6941.2006.00202.x

Watanabe, M., van der Veen, S., Nakajima, H., and Abee, T. (2012). Effect of respiration and manganese on oxidative stress resistance of Lactobacillus plantarum WCFS1. Microbiology 158, 293-300. doi: 10.1099/mic.0.051250-0

Yamamoto, Y., Gaudu, P., and Gruss, A. (2011). "Oxidative stress and oxygen metabolism in lactic acid bacteria," in Lactic Acid Bacteria and Bifidobacteria: Current Progress in Advanced Research, eds K. Sonomoto and Y. Atsushi (Poole: Caister Academic Press), 91-102.

Zhang, Y., and Li, Y. (2013). Engineering the antioxidative properties of lactic acid bacteria for improving its robustness. Curr. Opin. Biotechnol. 24, 142-147. doi: 10.1016/j.copbio.2012.08.013

Zotta, T., Ianniello, R. G., Guidone, A., Parente, E., and Ricciardi, A. (2013). Selection of mutants tolerant of oxidative stress from respiratory cultures of Lactobacillus plantarum C17. J. Appl. Microbiol. 116, 632-643. doi: 10.1111/jam. 12398

Zotta, T., Parente, E., and Ricciardi, A. (2017). Aerobic metabolism in the genus Lactobacillus: impact on stress response and potential applications in the food industry. Appl. Microbiol. 122, 857-869. doi: 10.1111/jam.13399

Zotta, T., Ricciardi, A., Guidone, A., Sacco, M., and Muscariello, L. (2012). Inactivation of ccpA and aeration affect growth, metabolite production and stress tolerance Lactobacillus plantarum WCFS1. Int. J. Food Microbiol. 155, 51-59. doi: 10.1016/j.ijfoodmicro.2012.01.017

Zotta, T., Ricciardi, A., Ianniello, R. G., Parente, E., Reale, A., Rossi, F., et al. (2014). Assessment of aerobic and respiratory growth in the Lactobacillus casei group. PLOS ONE 9:e99189. doi: 10.1371/journal.pone.0099189

Zotta, T., Ricciardi, A., Parente, E., Reale, A., Ianniello, R. G., and Bassi, D. (2016). Draft genome sequence of the respiration-competent strain Lactobacillus casei N87. Genome Announc. 4:e00348-16. doi: 10.1128/genomeA.00348-16

Conflict of Interest Statement: The authors declare that the research was conducted in the absence of any commercial or financial relationships that could be construed as a potential conflict of interest.

Copyright (c) 2018 Maresca, Zotta and Mauriello. This is an open-access article distributed under the terms of the Creative Commons Attribution License (CC BY). The use, distribution or reproduction in other forums is permitted, provided the original author(s) and the copyright owner are credited and that the original publication in this journal is cited, in accordance with accepted academic practice. No use, distribution or reproduction is permitted which does not comply with these terms. 